THE VERTICAL MULTINATIONAL ENTERPRISE AND INTERNATIONAL TRADE

\author{
by \\ Denise Eby Konan
}

Working Paper No. 96-1

February 1996 


\title{
THE VERTICAL MULTINATIONAL ENTERPRISE AND INTERNATIONAL TRADE
}

\author{
Denise Eby Konan"
}

University of Hawaii at Manoa

February 1996

\begin{abstract}
By explicitly modeling a distortion in the intermediate goods sector, I develop a model of an endogenous vertical multinational enterprise. Firms invest abroad to lower cost of multi-stage production. The implications for international trade and investment differ markedly from the conventional wisdom of multinationals. Particularly, intra-firm trade in intermediates implies vertical investment complements rather than substitutes for trade. The decision to become a multinational depends on the level of foreign factor prices, nature of competition with foreign suppliers, transport, tariff, and subsidiary plant costs. Marginal change in tariff may result in welfare jumps as firm configuration shifts.
\end{abstract}

JEL Codes $\quad$ F12, F23, L11

Keywords: Multinational Enterprise, Vertical Integration

"Department of Economics, University of Hawaii at Manoa, 2424 Maile Way, Honolulu, Hawaii, 96822. Phone 808-956-6310 Fax 808-956-4347 email konan@hawaii.edu. 


\title{
THE VERTICAL MULTINATIONAL ENTERPRISE AND INTERNATIONAL TRADE
}

\begin{abstract}
By explicitly modeling a distortion in the intermediate goods sector, I develop a model of an endogenous vertical multinational enterprise. Firms invest abroad to lower cost of multi-stage production. The implications for international trade and investment differ markedly from the conventional wisdom of multinationals. Particularly, intra-firm trade in intermediates implies vertical investment complements rather than substitutes for trade. The decision to become a multinational depends on the level of foreign factor prices, nature of competition with foreign suppliers, transport, tariff, and subsidiary plant costs. Marginal change in tariff may result in welfare jumps as firm configuration shifts.
\end{abstract}

JEL Codes: F12, F23, L11

Keywords: Multinational Enterprise, Vertical Integration 


\section{Introduction}

Over the past decade inward direct foreign investment has grown within some developing and newly industrialized economies, particularly in Southeast Asia, at a remarkable rate. Casual observation implies that direct foreign investment (DFI) inflow in these countries tends to be dominated by industries with multi-stage production (vertical industries) in pursuit of low-cost labor. As Wells (1993) observes, the output of these cost-conscience investors is also frequently destined for global, rather than local, markets. North-South trade in goods frequently reflects differences in factor endowments as characterized by standard Hecksher-Ohlin models. Likewise, we might expect the composition of North-South DFI to reflect endowment differences such that inward DFI occurs in sectors that intensively employ the country's abundant resources. ${ }^{1}$

That some multinational enterprises (MNEs) invest abroad to lower production costs is perhaps not surprising. Yet the bulk of the new MNE theory and policy analyses focus on market access incentives for DFI [Markusen 1995, 1984, Horstmann and Markusen 1992, 1989, Konan 1996a, b. Helpman 1984, Ethier and Horn 1990, and Ethier 1986]. The conventional wisdom that emerges is summarized by the "convergence theory" of Markusen and Venables (1994). Multinationals are more likely to exist when tariff or transport barriers are high, incomes are high, and countries' endowments, technologies, and factor prices are similar.

The multinational described by this literature is generally horizontally integrated, producing essentially the same line of goods in multiple geographical locations. In horizontal MNEs the value of intangible assets is high relative to firm market value, as these assets are the source of scale economies and are difficult to trade at arm's length. Intra-firm technology transfers result in local production that is a substitute for arm's length trade in final goods.

\footnotetext{
${ }^{1}$ Aside from industry case studies, little empirical work exists on this issue.
} 
We must be quite cautious about extending the results of the convergence theory too readily to developing and newly industrialized economies. While the approach is important, its application resides largely in investment flows between similar advanced countries where DFI is likely to represent technology transfers Indeed, horizontal multinational models ignore aspects of global multinational activity, such as intra-firm trade in intermediate goods, that are better understood in a North-South context. In addition, the convergence theory is unable to explain neither the significant inflows of direct investment into less developed economies nor the rise in this investment as developing economies liberalize trade policy

Very few formal models have been forthcoming for intra-firm trade in intermediate goods. One exception is Caves (1982) who presents an informal description of the multi-stage MNE in which vertical integration occurs to internalize a distortion, such as imperfections in intermediate goods markets stemming from contract, information, and transaction costs. With scale economies at the input stage of production, the model of Helpman (1985) considers the location choice of MNE plant production as a function of differential factor prices. The Helpman model treats the ownership decision to vertically integrate as exogenous and vertical arm's length transactions are not considered In models without DFI, Spencer and Jones (1992) and Rodrik and Yoon (1989) model government policy when a domestic firm attains an input produced more cheaply abroad from a vertically integrated foreign supplier. As both firms compete in the final good market, the price set by a foreign supplier is above that set by a monopolist producing only the input.

In this paper, I provide an example of an incentive for North-South multinational activity based on intra-firm intermediate goods trade. MNEs invest abroad in various stages of production to lower the cost of supplying an input rather than to gain access to foreign consumer markets. 
The focus of this paper is on the question of why a firm becomes a vertical MNE rather than an importer or domestic producer of an intermediate good. Vertical DFI is treated as an endogenous decision for intermediate good sourcing. A firm decides whether to invest, either domestically or internationally, in the production of an intermediate input or to buy from a foreign monopolist. Plant investment, location, and production decisions are endogenous for a two-stage production process in which factors are used in different proportions. Several of the model's predictions differ dramatically from those of the theory of horizontal MNEs. For example, while an important precondition for horizontal investment, firm-specific assets do not play a role in the decision to become a vertical MNE. Instead, subsidiary-level plant costs may influence the choice of firm configuration. High transport costs provide a tariff-jumping incentive for horizontal investment but act to discourage foreign verticalintegration in favor of inefficient domestic production. Thus, subsidiary output thus is a complement. not a substitute, to headquarter production.

Less obvious is the relationship between international factor price differences and the decision to become a vertical multinational. A necessary condition for vertical DFI is some cost advantage of foreign production such as less-expensive foreign wages. I simulate the relationship between firm configuration and factor prices with linear final demand and two forms of vertical competition. Given low foreign wages, the ownership decision (MNE versus ARM) is sensitive to both factor prices and the nature of vertical competition between upstream and downstream firms. When the potential multinational's demand for the intermediate good is a small share of total intermediate demand, the oligopolistic markup on intermediate price is independent. Thus MNE production emerges when foreign wages are moderately low (and markups are moderately high) while arm's length trade emerges for very low wages (and low markups). Alternatively, when intermediate demand by the potential multinational is a significant share of total demand oligopolistic markups is negatively correlated to 
wages. Thus an MNE arises with very low foreign wages while arm's length trade arises with moderately low wages

The paper proceeds as follows. In section 2, a generalized model is developed in which production requires two stages: unskilled labor-intensive with an intermediate good as an output and skilled labor-intensive. With imperfect competition at both stages of production, the final good producer's choice of firm configuration (domestic integration, imports, or MNE) is endogenous. A linear demand example is considered in section 3. In section 4 , I conduct a brief welfare analysis of trade policy with endogenous vertical firm configuration. I conclude with summary comments in section 5 .

\section{The Model}

There are two countries, home and foreign (denoted by superscript ${ }^{*}$ ). Each has a workforce

of skilled $\left(S, S^{*}\right)$ and unskilled $\left(L, L^{*}\right)$ labor that receives payments $\left(s, s^{*}\right)$ and $\left(w, w^{*}\right)$, respectively. Home is relatively skilled-labor and factor prices differ between countries. Labor is immobile between countries but transboundary equity ownership is permitted through direct foreign investment (DFI). Our focus is on two vertically related industries, that of an intermediate good $(Z)$ and a final good $(X)$.

Assume an oligopolistic industry with $n$ symmetric firms produce a homogenous product, $Z$ in the foreign country. World inverse demand for $Z$ units, $p_{z}(Z)$, is assumed to be twice differentiable where market supply is given by $Z=\Sigma^{n}{ }_{i=1} z_{i}$. Let the corresponding market demand function be $z\left(p_{z}\right)$.

$Z$ is produced with unskilled labor inputs at a constant marginal cost ( $w$ or $\left.w^{*}\right)$. Entry into $Z$ production, in either country, requires a fixed plant cost of $G$. Thus $Z$ is naturally oligopolistic and produced with plant-level economies of scale. The profit function for the $i$ th firm is given by 


$$
\pi_{z i}=p_{z}(Z) z_{i}-w^{*} z_{i}-G
$$

Let $\lambda=\partial Z / \partial_{i}$ be a firm's conjectural derivative or belief about the way market output responds to changes in its output. ${ }^{2}$ Solving for the first-order condition of (1) and by the assumption of symmetric $Z$ firms, we obtain the equilibrium price of $Z, \widetilde{p}=p(\widetilde{Z})$ as given by equation 2

$$
\begin{gathered}
p(\widetilde{Z})=\mu_{z} w^{*}, \text { where } \mu_{z}=\left(1-\sigma / \varepsilon_{z}\right)^{-1}>1, \\
\sigma=\lambda / n, \quad \varepsilon_{z}=-\frac{\partial z}{\partial p_{s}} \frac{p_{z}}{Z}
\end{gathered}
$$

Thus a $Z$ firm's marginal cost markup, $\mu_{z}$, is negatively correlated with the market elasticity of demand, $\varepsilon_{z}$, and positively correlated with the conjectural elasticity, $\sigma$. As generally assumed, $\varepsilon_{z}$ is a decreasing function of $Z$ quantity demand.

A home-based monopoly supplies a homogenous product, $X$. World inverse demand for $X$ units, $p_{x}(X)$, is assumed to be twice differentiable, with no income effects. Let $x\left(p_{x}\right)$ corresponding demand function. Each unit of final $X$ demand is produced from one unit of skilled labor and one unit of an intermediate good $Z$ with Leontief technology and constant marginal cost. Fixed costs, $F$, are sufficiently large so as to make $X$ naturally monopolistic with increasing returns to scale technology. ${ }^{3}$ As we will see below, the cost function for $X$ depends on the ownership and location configuration of production, which is endogenous. For simplicity, we assume home has an absolute cost advantage in skilled labor that is sufficient to insure $X$ production locates at home.

Imperfect competition in $X$ and $Z$ industries creates a version of the familiar successive monopoly distortion. ${ }^{4}$ The $X$ monopolist sets a markup on arm's length marginal cost (including the $Z$

${ }^{2}$ So $\lambda=1$ implies Cournot conjectures.

${ }^{3}$ That is, the market size is sufficiently small to make non-monopoly production of $X$ unprofitable for all firms in a post-entry Nash equilibrium.

${ }^{4}$ See Perry (1989) and Tirole (1989) for a review of this literature. 
markup) rather than the lesser true marginal cost. An incentive exists to internalize this distortion by vertically integrating production. This paper considers the distinct advantages and costs of alternative $Z$ plant location and ownership configurations within the $X$ industry in order to examine the characteristics of an endogenous vertical MNE.

The equilibrium $X$ firm configuration is determined by a two-step procedure. In step one, the $X$ firm makes a choice of location and ownership of intermediate supply over three options: arm's length imports from foreign oligopolists ("ARM" regime); imports from a vertically integrated foreign subsidiary ("MNE" regime); and domestic supply from a vertically integrated plant ("DOM" regime). In step two, the $X$ firm selects the profit-maximizing price of $X$. The programming problem is solved backwards, beginning with the optimal pricing decision for each configuration.

\section{ARM Profit Maximization}

Consider a scenario in which the $X$ firm elects to import $Z$ at arm's length. As is evident by the wide body of literature on vertical distortions (Perry 1989), imperfect competition between the upstream $X$ and downstream $Z$ firms could take a variety of forms. In general, both $X$ and $Z$ firms set a price above marginal cost creating a double marginalization that implies lower output then is industryprofit maximizing.

In this case, the $X$ firm pays a markup $\mu_{z}$ over $Z$ 's marginal cost $w^{*}$ such that $\widetilde{p}_{z}=\mu_{z} w^{*}$. With a specific tariff on $Z$ imports, $\tau_{z}$, the home monopolist's cost function is given by

$$
C_{x}^{a v m}=F+\left[s+\mu_{z} w^{*}+\tau_{z}\right] X
$$

The firm selects price to maximize profits given by 


$$
\pi^{a m m}=\left(p_{x}(X)-s-\mu_{z} w^{*}-\tau_{z}\right) X-F
$$

As a monopolist supplier of $X$, the optimal price of $X, p_{x}$, is a markup $\mu_{x}$ over marginal cost where $\mu_{x}=\left(1-1 / \varepsilon_{x}\right)^{-1}, \varepsilon_{x}=-\frac{\partial X}{\partial p_{x}} \frac{p_{x}}{X} \cdot 5$ For simplicity, I assume the $X$ firm does not avail itself of any monopsony power in the $Z$ market. Differentiating and solving for the first order conditions of the home firm's programming problem yields

$$
\widetilde{p}_{x}=\mu_{x}\left(s+\mu_{z} w^{*}+\tau_{z}\right)
$$

Thus the home firm adds a successive markup over its marginal cost, which does not reflect the true marginal cost of $Z$ but rather $p_{z}=\mu_{z} w^{*}$. The ARM regime is always Pareto inefficient as the consumer price is higher and aggregate producer surplus is lower relative to a cooperative solution where joint $X-Z$ industry profits are maximized. It should be noted that there is an incentive for $X$ and $Z$ firms to cooperate through more complex contractual arrangements, such as a joint venture agreement. ${ }^{6}$ As our focus is on a firm's decision to become an MNE, we save an analysis of alternative forms of DFI for future research.

Pareto inefficiency of arm's length purchase of $Z$ provides an incentive to vertically integrate the production process. The firm's administration makes joint profit maximization decisions across vertically integrated plants, thus avoiding the problem of double-marginalization. In this model, the home firm has two options for location of an integrated $Z$ plant: MNE production through a foreign $Z$ subsidiary and DOM production with a domestic $Z$ plant.

\footnotetext{
${ }^{5}$ Note $\mu_{x}$ is not a constant but rather a function of $X$ output.

${ }^{6}$ See Ethier (1986) for a discussion of the role of contractual arrangements in direct foreign investment.
} 


\section{MNE Profit Maximization}

A home-based MNE has two main advantages: access to low-cost foreign labor inputs and the ability to set jointly profit maximizing prices. The creation of a foreign subsidiary, however, imposes added costs on the firm. A foreign subsidiary faces costs beyond those of independent local producers such as language translators, local network development, and host government discrimination. Although a vertical distortion and differential international factor prices are necessary, these conditions are insufficient to assure equilibrium vertical DFI when offsetting costs are present.

Transaction costs of DFI may be either variable, $t^{*}$, or fixed, $T^{*}$ or both. Imports of $Z$ also incur a home tariff of $\tau_{z}$. With subsidiary plant start-up cost of $Z$ production, $G$, as well as firm-level fixed cost of $X$ production, $F$, the global cost function for MNE production is given by

$$
C_{x}^{m n e}=F+G+T^{*}+\left[s+w^{*}+t^{*}+\tau_{z}\right] X
$$

Implying the MNE profit function

$$
\pi_{x}^{m n e}=\left[p_{x}(X)-s-w^{\prime}-t-\tau_{z}\right] X-F-G-T^{*}
$$

and corresponding first-order condition of optimization. ${ }^{7}$

$$
\widetilde{p}_{x}^{m n e}=\mu_{x}\left[s+w^{*}+t^{*}+\tau_{z}\right]
$$

\section{DOM Profit Maximization}

A second form of vertical integration is domestic where commonly owned $X$ and $Z$ plants are located at home. The DOM firm is able to set a jointly profit maximizing price and avoid transactions and tariff costs of extending equity ownership abroad This firm configuration, however, entails a

\footnotetext{
${ }^{7}$ The home unskilled wage, $w$, differs from foreign wage $w^{*}$ by some margin. If $w=w^{*}+t^{*}+\tau_{z}$ then $\widetilde{p}_{x}^{m n e}=\widetilde{p}_{x}^{d o m}$.
} 
higher marginal production cost for $Z$ as home unskilled wages $w$ exceeds that of the foreign country $w$ The cost function for the DOM regime is given by

$$
=F+G+[s+w] X
$$

Implying the DOM profit function

$$
\pi_{x}^{d o m}=\left[p_{x}(x)-s-w\right] X-F-G
$$

Solving the programming problem yields the equilibrium price

$$
\widetilde{p}_{x}^{d o m}=\mu_{x}[s+w]
$$

\section{Market Structure Solution}

In stage one of the programming problem, the $X$ firm selects the optimal method of supplying intermediate demand. This decision is made by comparing profit levels attainable under alternative $Z$ plant location and ownership configurations, equations 4,7 , and 10 .

$$
\begin{gathered}
\tilde{\pi}_{x}^{a r m}=\left(\mu_{x}-1\right)\left(s+\mu_{z} w^{*}+\tau_{z}\right) x\left(\tilde{p}_{x}^{d o m}\right)-F \\
\tilde{\pi}_{x}^{m n e}=\left(\mu_{x}-I\right)\left(s+w^{*}+t^{*}+\tau_{z}\right) x\left(\widetilde{p}_{x}^{m n e}\right)-F-G-T^{*} \\
\tilde{\pi}_{x}^{d o m}=\left(\mu_{x}-1\right)(s+w) x\left(\widetilde{p}_{x}^{d o m}\right)-F-G \\
\tilde{\pi}_{x}=\max \left[\tilde{\pi}_{x}^{a r m}, \tilde{\pi}_{x}^{m n e}, \tilde{\pi}_{x}^{d o m}\right]
\end{gathered}
$$

The equilibrium firm configuration may shift in response to marginal changes in relevant parameters. Our ability to do comparative static analysis is constrained by the discontinuity of the equilibrium profit function, $\tilde{\pi}_{x}$ All else equal, marginal changes in a parameter may imply a shift of firm configuration rather than a marginal price, output or profit response Nonetheless, some important conclusions may be reach concerning the firm's decision to vertically integrate, either 
domestically or internationally, or to import $Z$ at arm's length as the graphical illustration of figure 1 demonstrates.

Certain parameters influence equilibrium firm configuration similarly in either a vertical or horizontal distortion. One factor believed to discourage horizontal MNEs is the existence of discriminatory costs associated with DFI (Caves 1982, Markusen 1995). Figure one depicts the relationship between equilibrium profits in alternative vertical regimes and respective transaction costs $T^{*}$ and $t^{*} \cdot{ }^{8}$ With low $Z$ plant fixed costs, $G$, a vertical MNE equilibrium is associated with transaction costs below the critical levels $\left(\hat{T}^{*}, \hat{t}^{*}\right)$ Transaction costs above $\hat{T}^{*}$ and $\hat{t}^{*}$ are associated with non-DFI market structures.

It is also believed that horizontal MNEs arise when subsidiary fixed costs is relatively low, Horstmann and Markusen (1992). We observe a comparable result in a vertical industry context. The only firm configuration under which $Z$ plant-level fixed cost $G$ is avoided is one of arm's length $Z$ import from an independent supplier. A precondition for vertical DFI is that $G$ is relatively low, as we will demonstrate in the following section.

In contrast, consider the firm-specific fixed cost $F$. In horizontal MNE models, $F$ serves as a globally-joint input across subsidiary plants. In the presence of scale economies horizontal MNEs are more likely to exist in equilibrium when these firm-level inputs are relatively high. Such reasoning does not extend to vertical DFI as the equilibrium choice of vertical subsidiary ownership is independent of $F$ that cannot be avoided by alternative regime choice.

${ }^{8}$ The slope $\partial \pi^{m e} / \partial T^{*}=-1$, while

$$
\frac{\partial \pi^{m n e}}{\partial t^{*}}=\left(\mu_{x}-1\right)\left(s+w^{*}+t^{*}+\tau_{z}\right)\left(\frac{\partial x}{\partial t^{*}}-x\right) \text { and } \frac{\hat{\sigma}^{2} \pi^{m n e}}{\partial t^{2}}=\left(\mu_{x}-1\right)\left(s+w^{*}+t^{*}+\tau_{z}\right)\left(x-\frac{\partial^{2} x}{\partial t^{2}}\right)
$$


inal $X$ firm wil $\quad$ import $Z$ at if the oligop markup $\mu_{z}$ is abo the threshold levi gur The ku $\mu_{z}$ may be high for ety of easons the her of sompetit may he imited is lati rel small firms may ude to degree (. the onjectur rati is high the obal $Z$ arket may be fairly melaste $\boldsymbol{\varepsilon}_{\boldsymbol{z}} \quad$ 1): or the $X$ firm may face an eilastic $Z$ supp functi

\section{A Linear Demand xample}

ontinu convenient to imnose functional forms and 'alues. W then ulate equi firm configurati and dra pairwise compart of interesung parameters the equilibrium nirm nfigurati ider ìnear demand ampi hereby $\left(p_{x}\right)$ Assume the ket markud $\mu_{z}$, independent of $X$ demand This ump equ maikul over marginal cost $(m c \quad$ (: $\quad$ rice of ( $\quad$ :) and esponding profits gi ren hiv

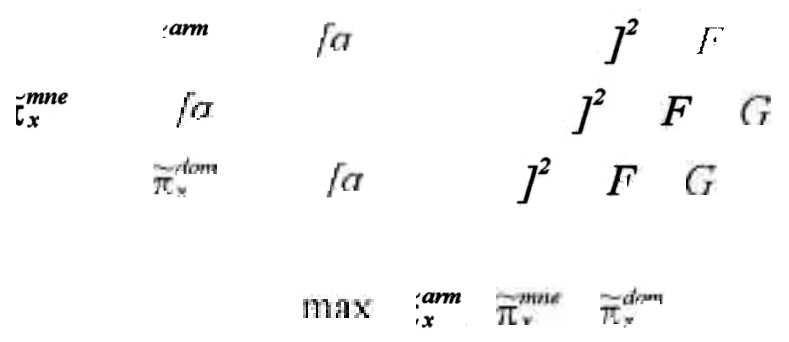

T provid indication of the range of potential twi forms of vertical distortion considered First assume $X$ market demand ery mal to nhal market dernand. This imp ies that the industry markup independent of $X$ demand $\Lambda s$ second $Z$ is only demanded an intermediate good the $\boldsymbol{X}$ market 

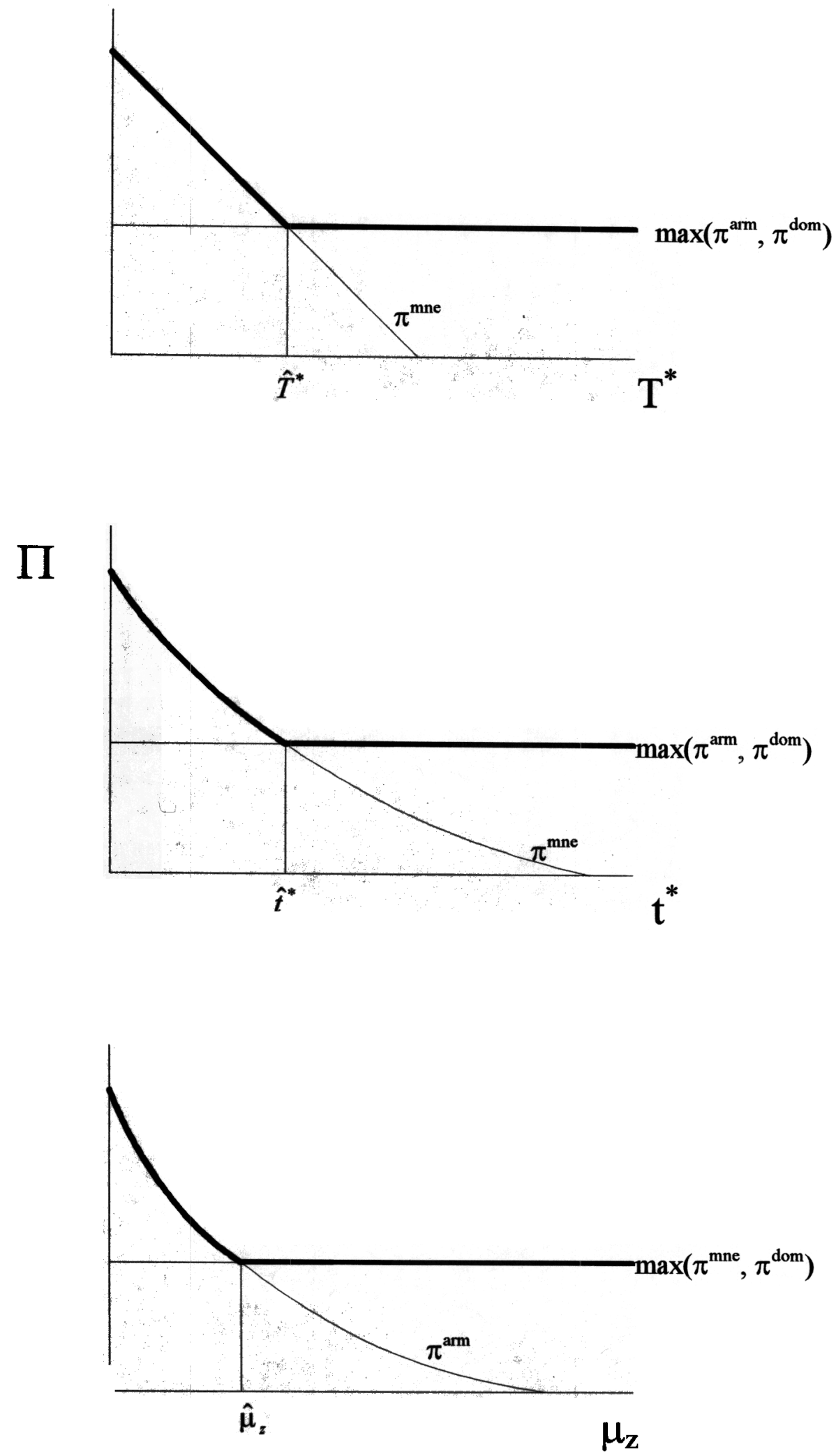

Figure 1: Comparative Statics 


\section{Case One: Independent Z-markup}

In case one, the $Z$ market is significantly larger than $X$-industry input demand. Hence the $Z$ markup $\mu_{\mathrm{z}}$ is independent from $X$ firm's decisions and $\widetilde{p}_{z}=\mu_{z} w^{*}$

A primary reason for locating $Z$ production processes abroad is the availability of low cost unskilled labor. Figure 2 shows the equilibrium firm configuration for various sets of unskilled wage

coordinates $\left(w, w^{*}\right)$ holding other parameters fixed. The depicted loci give the set of coordinates for which the home firm is indifferent between two firm configurations. For example, the $X$ firm is indifferent between ARM and MNE configurations when profits are equal under the alternative regimes or equivalently

$$
\widetilde{\pi}_{x}^{a m m}-\widetilde{\pi}_{x}^{m n e}=\frac{1}{4}\left[a-s-\mu_{z} w^{*}-\tau_{z}\right]^{2}-\frac{1}{4}\left[a-s-w^{*}-t^{\prime}-\tau_{z}\right]^{2}+G+T^{*}=0
$$

Because the expression is independent of home wages $w$, the boundary between ARM and MNE regimes is a horizontal line. Above this threshold $w^{*}$, the transaction cost of becoming an MNE is less than the cost of double marginalization under the ARM regime. With a constant $Z$ markup, as the differential between home and foreign wages increases foreign oligopolists have an enhanced ability to mark prices above marginal cost. High $Z$ profit margins (associated with high $w^{*}$ ) provide an incentive for MNE investment in a foreign $Z$ subsidiary

Consider the boundary between DOM and MNE regimes. To the left of this locus, foreign wages are not low enough to compensate for the transportation costs and differential transaction costs that would be incurred by an MNE. As foreign wages fall or, equivalently, home wages rise an MNE equilibrium is more likely to occur. This result corresponds to that of Helpman's (1985) model of vertically integrated MNE plant location. 


\section{foreign wage}

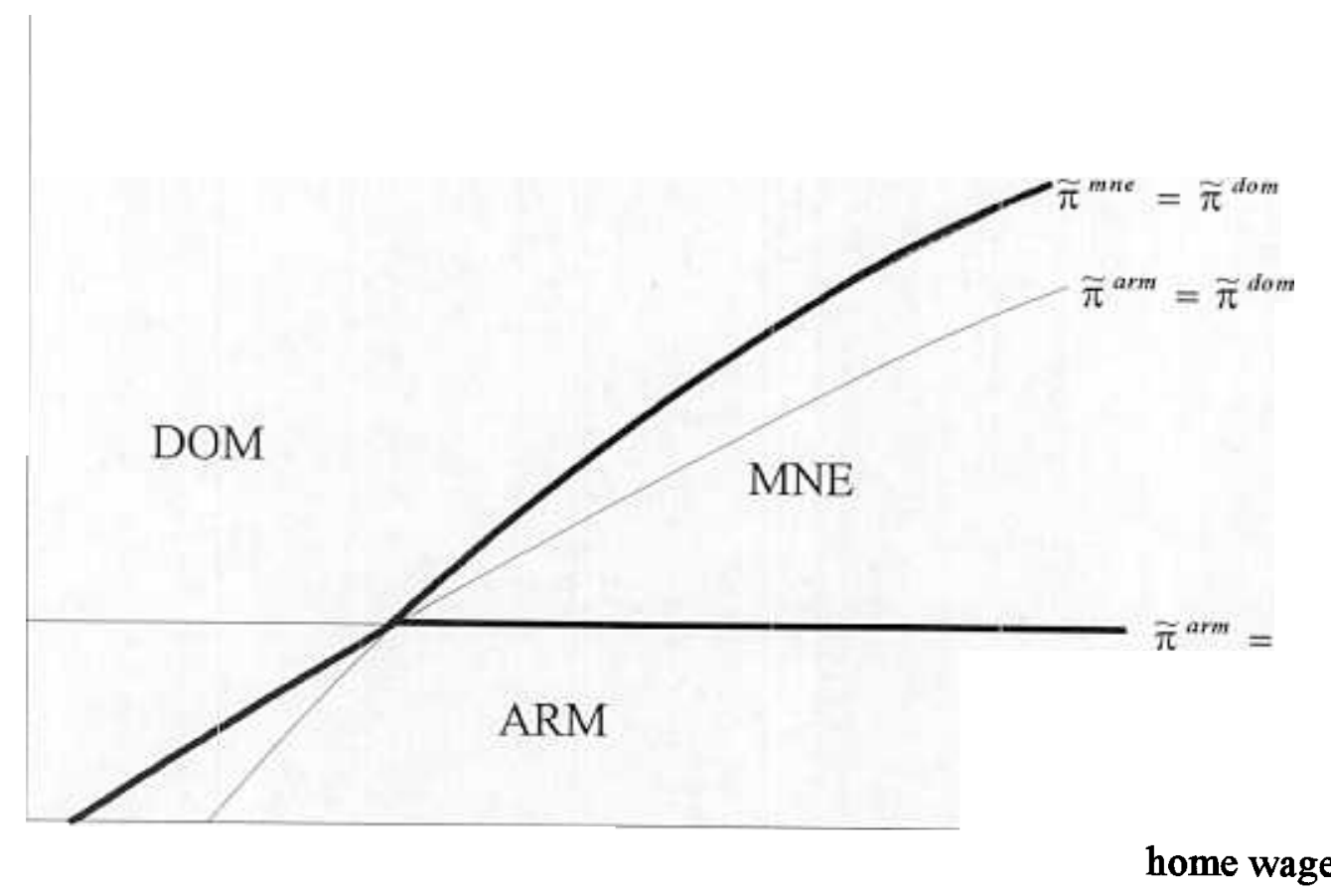

Figure 2: Case One, Firm Configuration and Unskilled Labor

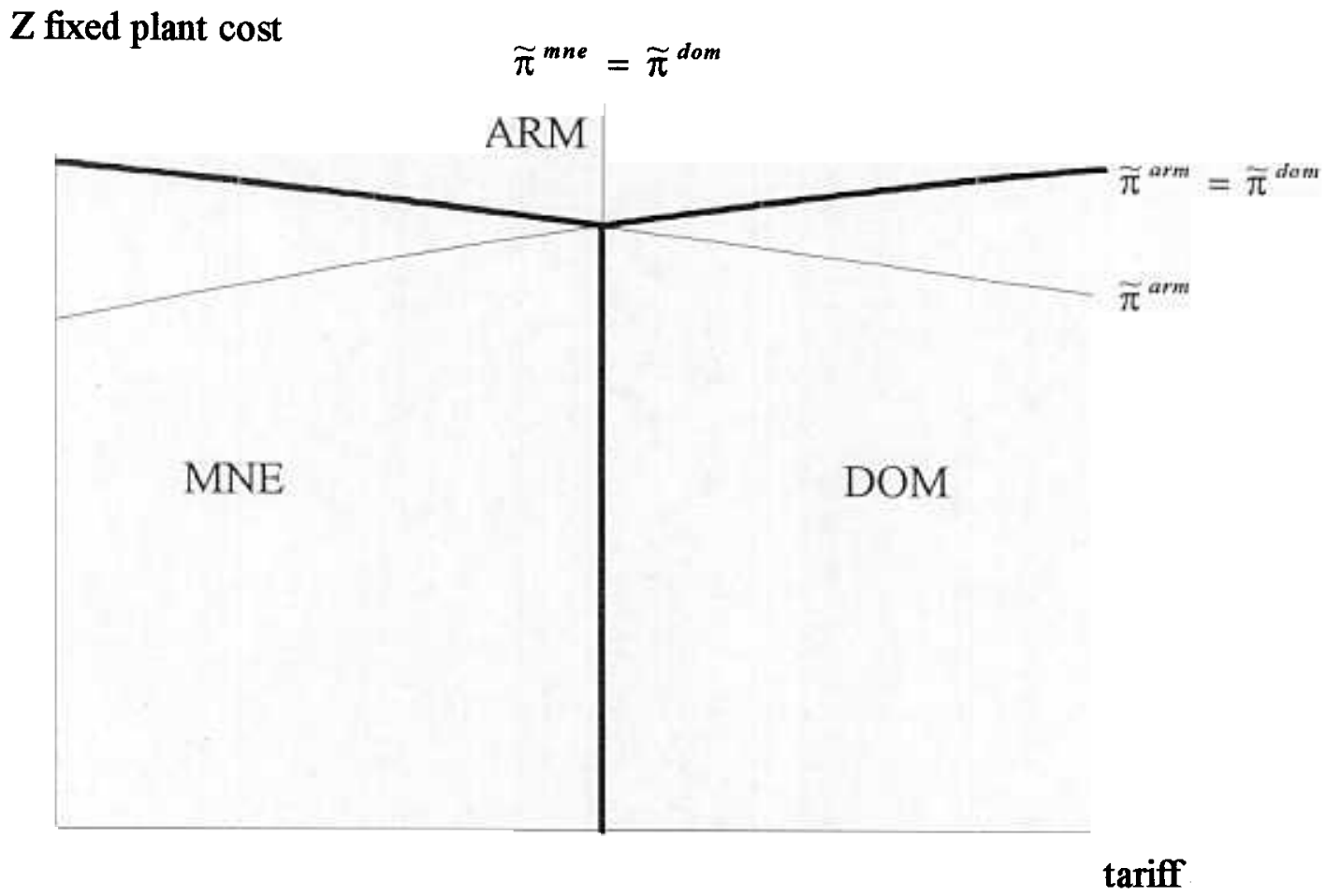

Figure 3: Firm Configuration and Trade Policy 
Likewise, the boundary between DOM and ARM regimes has positive slope and curvature. In this case, the benefits from wage differentials must sufficiently outweigh the cost of foreign oligopoly pricing and transportation before the ARM regime is selected as an equilibrium market structure.

This finding is in direct contrast to the "convergence hypothesis" of Markusen (1995) that international commerce between countries of similar size and relative factor endowments is more likely to be dominated by multinationals. In this view horizontal MNEs arise endogenously when they are able to transfer firm-specific increasing returns to scale technology abroad at low cost The impetus for vertical DFI is markedly different as the benefits are production cost rather than consumer demand driven. Thus given significant oligopoly markups, the greater the disparity in wages between countries, the more likely international economic activity will be dominated by vertical multinationals

Consider the impact of the $Z$ plant-level fixed cost $G$ and the specific $Z$ tariff, $\tau_{z}$, on equilibrium firm configuration I derive loci of indifference between firm configurations in $\left(\tau_{z}, G\right)$ parameter space in figure 3 Recall the $X$ firm avoids $G$ only by importing $Z$ at arm's length The ARM equilibrium dominates both MNE and DOM for sufficiently high $G$. As in a horizontal MNE model, vertical MNEs are more likely to arise in industries with low subsidiary plant-level costs

Once again, I find an area of distinction between horizontal and vertical MNEs. Production by a horizontal MNE is import-competing and thus a substitute for international trade. Horizontal MNEs tend to arise when transportation and tariff barriers are relatively high. ${ }^{9}$ This "tariff-jumping" argument does not apply to a vertical MNE whose subsidiary production and intra-firm export of intermediate goods is a complement to international trade In this case, the $X$ firm spares the specific

\footnotetext{
${ }^{9}$ See Markusen (1995) for a review of these horizontal MNE models.
} 
tariff $\tau_{z}$ cost only by producing $Z$ domestically. Thus a DOM equilibrium is characterized by relatively low $G$ and high $\tau_{z}$ while an MNE equilibrium implies relatively low $G$ and low $\tau_{z}$.

\section{Case Two: Dependent Z-markup}

In the second linear demand example, $Z$ is a specialized component used only as an $X$ input. Without loss in generality, I maintain the assumption that the $X$ firm does not exploit monopsony buying power in the $Z$ market. Taking $p_{z}$ as given in arm's length $Z$ purchases, $X$ demand and hence $Z$ demand is derived from the equilibrium profit function $\widetilde{\pi}_{x}^{a r m}$ of the system of equations (13) and given by $\widetilde{X}=Z=\frac{1}{2}\left(a-\widetilde{p}_{z}-s-\tau_{z}\right)$ and corresponding inverse $Z$ demand $p_{z}=a-s-\tau_{z}-2 Z$. Assume Cournot-Nash competition between $Z$ firms or $\lambda=1$ Profit maximization of equation 1 implies a firm-level Cournot-Nash equilibrium inverse demand given by

$$
\widetilde{p}_{z}=\left(1+\frac{1}{n}\right)^{-1}\left(a-s-\tau_{z}+w^{*}\right)
$$

Substituting $p_{z}$ into $p_{x}$ and solving for subgame equilibrium $X$ profits of system (13), I obtain

$$
\tilde{\pi}_{x}^{a m m}=\frac{1}{4}(1+n)^{-2}\left(a-s-\tau_{s}-n w^{*}\right)^{2}-F
$$

The key difference between linear demand examples one (independent $Z$ markup) and two is the equilibrium firm configuration over unskilled wage space, figure 4. As in example one, the firm will not source $Z$ from abroad unless foreign wages are significantly lower than domestic wages to compensate for additional costs such as transportation. The DOM regime thus includes the $45^{\circ}$ line where $w=w^{\prime \prime} \quad$ The difference due to endogenous $Z$ markups is in the relationship between equilibrium firm configuration and unskilled wages in the ARM and MNE regimes In the arm's length regime of case one, foreign wages are marked up by a constant regardless of $X$ demand. The MNE equilibrium 


\section{foreign wage}

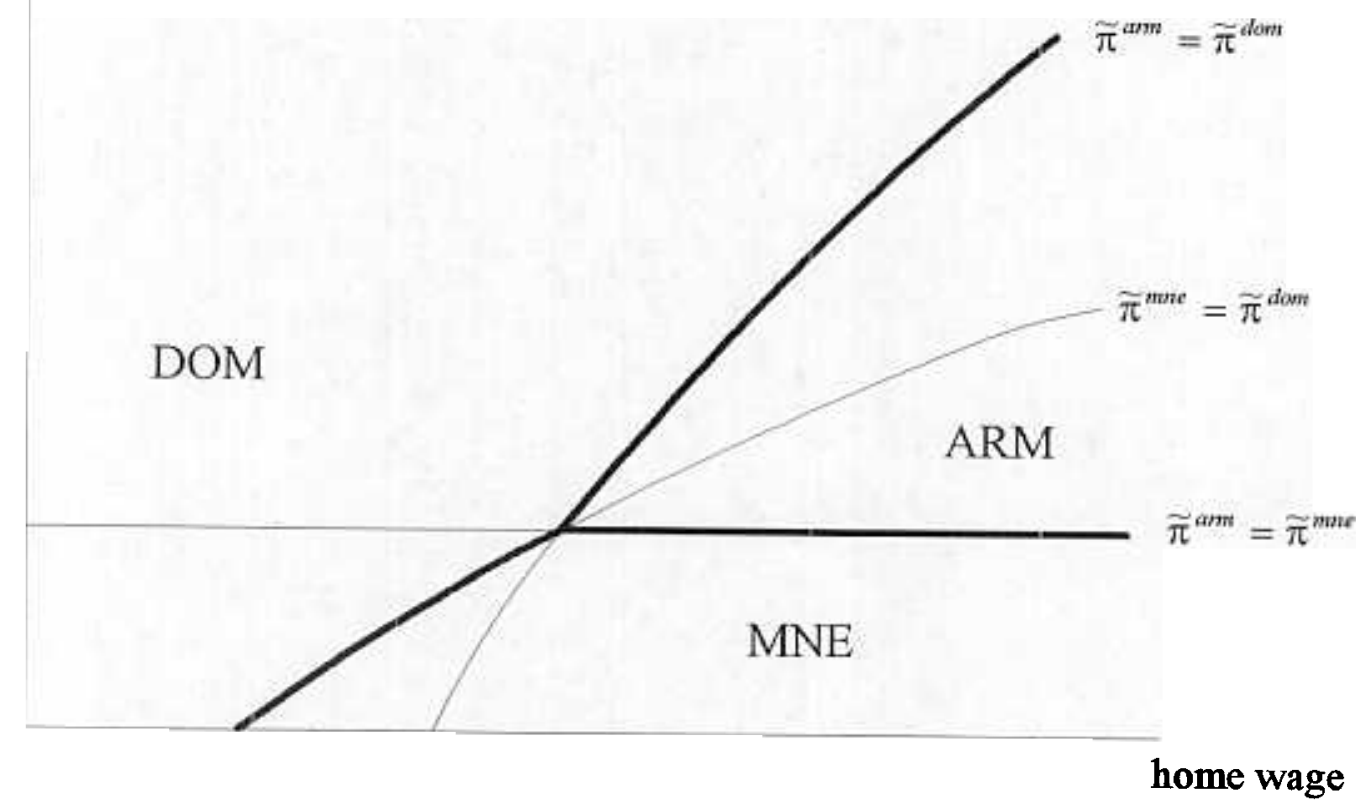

Figure 4: Case Two, Firm Configuration and Unskilled Labor 
thus dominates for wages above the threshold $\widetilde{\pi}_{x}^{a m}=\widetilde{\pi}_{x}^{m n e}$ as the arm's length markup becomes more burdensome. In case two, as $w^{*}$ rises $Z$ producers respond to decreasing demand by reducing their markup $\mu_{z}$ as $\partial \varepsilon_{x} / \partial X<0$. As the $X$ firm shifts the burden of high foreign wages to the $Z$ oligopolists, ARM dominates MNE configuration for foreign wages above the threshold boundary $\widetilde{\pi}_{x}^{a m m}=\widetilde{\pi}_{x}^{m n e}$

4. Trade Policy, Welfare, and Equilibrium Market Structure

In this section I analyze the effect of tariff policy in vertically related markets when firm configuration is endogenous. Consider the partial equilibrium home social surplus derived from the $X$ and $Z$ industries. National surplus, $W$, may be represented as the sum of consumer surplus $v(t)$, tariff revenue $\widetilde{Z}_{z}$, and equilibrium profits, $\widetilde{\pi}_{x} \cdot{ }^{10}$

$$
\begin{aligned}
& W=v(t)+\widetilde{Z} \tau_{x}+\tilde{\pi}_{x} \\
& \text { where } v(t)=\int_{\tilde{p}_{x}}^{\infty} x(t) d t
\end{aligned}
$$

As shown in section 3 , the equilibrium $X$ firm configuration is sensitive to the tariff rate. A small change in the tariff rate may result in a shift in input sourcing decisions, implying a corresponding jump in price, $Z$ imports, and profits. Welfare is thus discontinuous Additionally, as it attempts to avoid taxation the $X$ firm does not necessarily select the welfare maximizing firm configuration

The relationship between MNE source country welfare and $\tau_{z}$ is demonstrated with our linear demand example in figures 5 and 6 . For simplicity, assume $Z$ plant costs are relatively high and an

\footnotetext{
${ }^{10}$ Consumer surplus is employed as a welfare measure because there are no income effects. If we assume that tariff announcements are made prior to the firm's decision, then start-up costs $F$ and $G$ are fixed rather than sunk. In this case, producer profits are an accurate measure of producer surplus with constant marginal cost technology.
} 
welfare
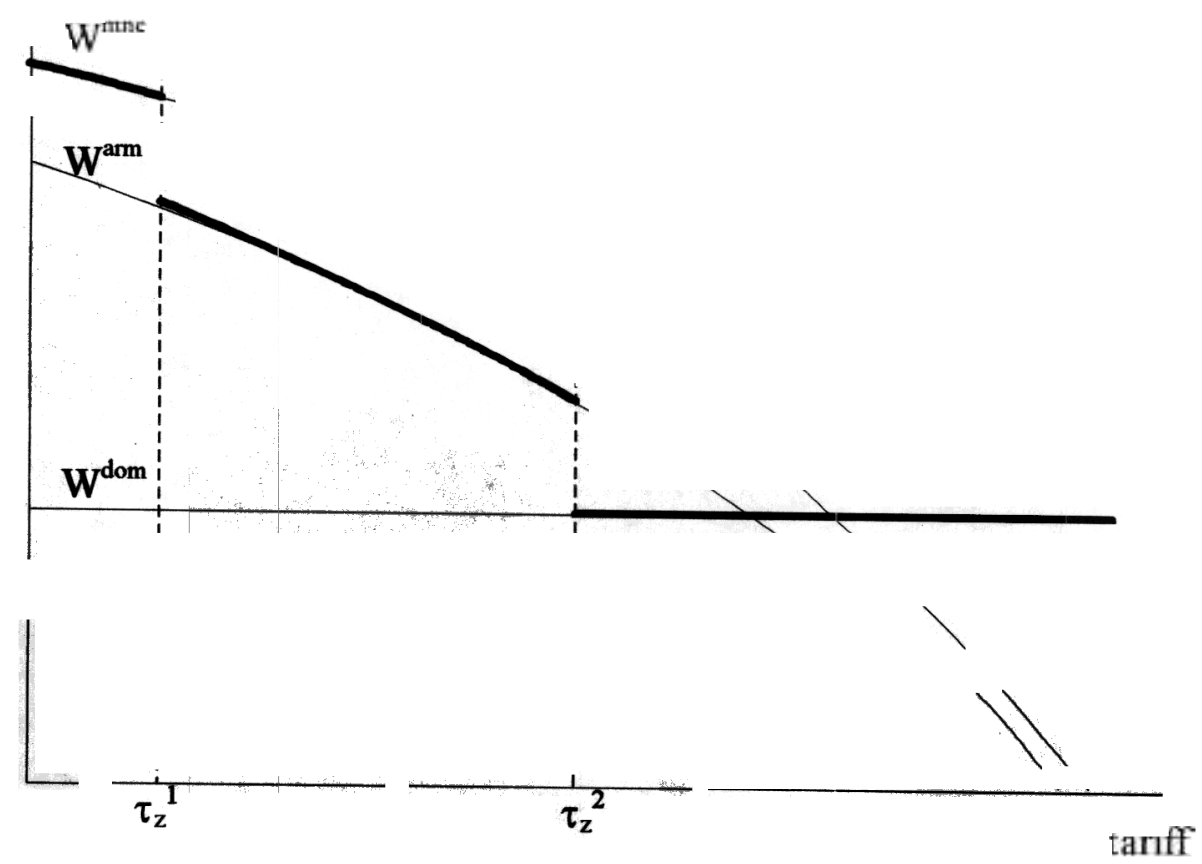

profit

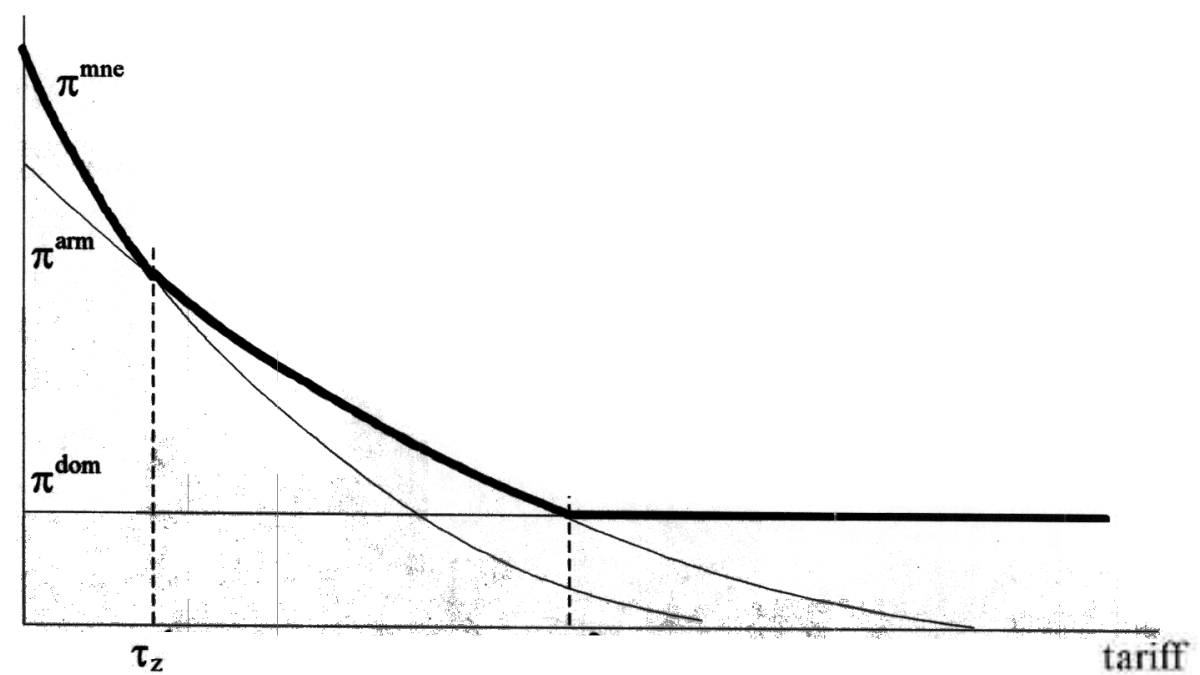

Figure Case One Welfare Analysis Trade Policy 
MNE exists in the absence of a tariff. $Z$ is only imported for use in $X$ production and home consumes a constant share of world $X$ output. In each case, bold curves give the (discontinuous) equilibrium welfare and profit functions while thin curves hold relevant firm configuration constant.

\section{Case One}

Figure 5 depicts equilibrium profits and welfare as a function of tariffs in the initial example where arm's length exports of $Z$ are marked up by a constant, $\mu_{z}$. I assume initial parameters whereby zero tariff and MNE production are socially and privately optimal As the tariff increases, both consumer surplus and profits decline as the firm's marginal cost and $p_{x}$ increase. With MNE ownership there is no possibility of improving terms of trade for $Z$ imports. At the critical tariff rate, the $X$ firm switches between MNE and ARM configurations. This implies a jump in welfare as profits are shifted abroad. For tariff rates beyond $\tau_{\mathrm{z}}{ }^{2}, Z$ will not be imported in equilibrium. A second jump in welfare may result as $Z$ production inefficiently shifts to the home country

Case Two

Our second illustration, figure 6, depicts equilibrium profits and social welfare as a function of tariff policy when using $Z$ only in production of $X$. Assuming no retaliation, the home government may exploit monopsony power over arm's length imports through tariff policy

Say the initial tariff rate implies the ARM regime will dominate or $\tau_{z} \in\left(\tau_{z}{ }^{1}, \tau_{z}{ }^{2}\right)$. A nation that maximizes welfare assuming the $X$ firm configuration is invariant to tariff policy would select the optimal tariff, $\tau_{z}$. Yet, $\tau_{z}{ }^{\prime}$ is locally-optimal rather than globally-optimal The welfare maximizing policy is one that eliminates the tariff, thus providing the impetus for outward investment in $Z$. 

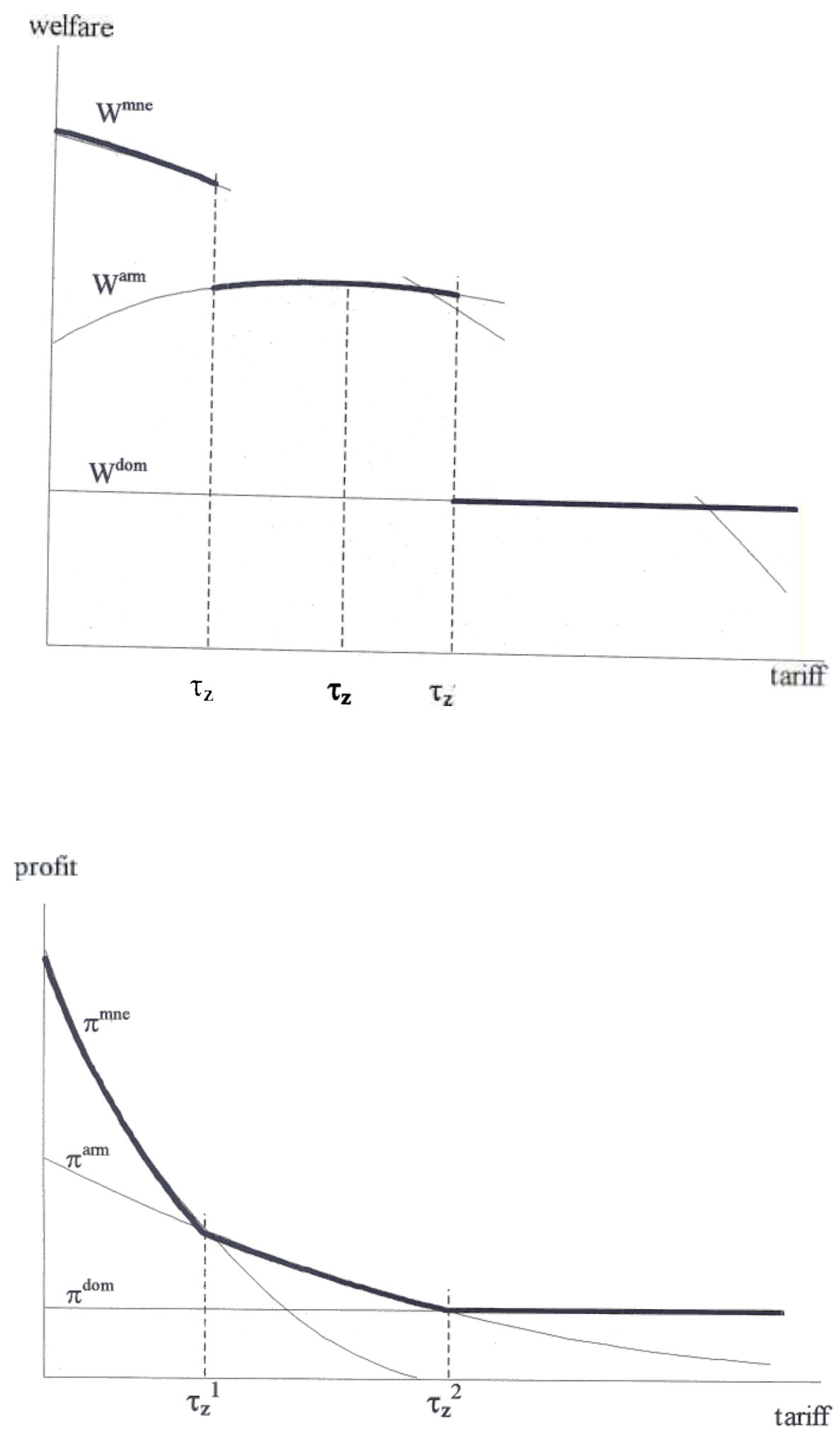

Figure Case Two Welfare Analysis of Trade Policy 


\section{Summary and Concluding Remarks}

By explicitly including the possibility of a distortion in the intermediate goods sector, I develop a model of an endogenous multinational enterprise that explains North-South direct foreign investment. The implications for international trade and investment differ markedly from the conventional wisdom of MNEs as set forth in the convergence theory, Markusen and Venables 1994. Foreign investment complements, rather than substitutes for, international trade while investment is more likely to emerge between countries of dissimilar endowments.

A firm has one of three configurations: domestic vertical integration; MNE vertical integration; or arm's length import of intermediate inputs at a marked up price. The home firm compares potential profitability under the range of plant location and ownership options for the lowskilled labor intensive intermediate good. The emergence of a vertical MNE was discussed in the context of basic parameters. Marginal changes in parameter specifications may lead to discontinuities in equilibrium price, profits, and welfare as the firm switches investment and production strategies. MNE activity is negatively correlated with oligopoly markups on inputs, DFI transactions costs, and intermediate plant-level fixed costs.

Less obvious is the relationships between firm configuration and international unskilled wage differentials. Two assumptions about bilateral competition between intermediate and final good demand were considered. In the first case the final good comprises a small fraction of market intermediate demand, implying an independent intermediate markup. As a result, harmonization in international unskilled wages implies domestic vertical integration. In contrast to the convergence theory of horizontal MNEs, significant factor price dispersion results in vertical MNE production for moderately low foreign wages and arm's length intermediate imports for very low foreign wages. 
Counter to the tariff-jumping argument for horizontal DFI, I find that low tariff rates are a precondition for an MNE equilibrium.

In the second case, I assume the intermediate good is a specialized component used only as an input for a monopolistic final good. The findings are similar to those of case one with one important exception. As foreign wages rise, oligopolist intermediate goods producers lower their equilibrium markup rates to preserve market demand. Thus arm's length exports of the intermediate good dominate when foreign unskilled wages are moderately low and a vertical MNE emerges for very low wages. Finally, marginal changes in trade policy are shown to have large welfare implications as equilibrium firm configuration shifts 


\section{REFERENCES}

Caves, R. E., 1982, Multinational Enterprise and Economic Analysis (Cambridge University Press, Cambridge).

Ethier, W.J., 1986, The Multinational Enterprise, The Quarterly Journal of Economics 101, 805-833.

Ethier, W.J. and H. Horn, 1990, Managerial Control of International Firms and Patterns of Direct Investment, Journal of International Economics 28, 25-45.

Helpman, E., 1984, A Simple Theory of International Trade with Multinational Corporations, Journal of Political Economy 92, 451-471.

Helpman, E., 1985, Multinational Corporations and Trade Structure, Review of Economic Studies 85, 443-457.

Horstmann, I. J. and J. R. Markusen, 1992, Endogenous Market Structures in International Trade (Natura Facit Saltum), Journal of International Economics 32, 109-130.

Horstmann, I. J. and J. R. Markusen, 1989, Firm Specific Assets and the Gains form Direct Foreign Investment, Economica 56, 41-48.

Konan, D. E., 1996a, Strategic Taxation of the Multinational Enterprise: A New Argument for Double Taxation, Journal of Public Economics, forthcoming.

Konan, D. E., 1996b, Transfer Pricing and the Strategic Taxation of Globally Joint Inputs, Review of International Economics 4(2), 202-210.

Markusen, J. R., 1995, The Boundaries of Multinational Enterprises and the Theory of International Trade, The Journal of Economic Perspectives 9, 169-189.

Markusen, J. R., 1984, Multinationals, Multi-plant Economies, and the Gains from Trade, Journal of International Economics 16, 205-224.

Markusen, J. R. and A. J. Venables, 1994, Multinational Firms and the New Trade Theory, manuscript.

Perry, M., 1989, Vertical Integration, in R. Schmalensee and R. Willig, eds., Handbook of Industrial Organization (North Holland: Amsterdam).

Rodrik, D. and C. H. Yoon, 1989, Strategic Trade Policy When Domestic Rival Firms Compete Against Vertically Related Rivals, National Bureau of Economic Research Working Paper No. 2916.

Spencer, B. J. and R. W. Jones, 1992, Trade and Protection in Vertically Related Markets, Journal of International Economics 32(1-2), 31-55.

Tirole, Jean, 1989, The Theory of Industrial Organization, (The MIT Press: Cambridge).

Wells, L. T., 1993, Mobile Exporters: New Foreign Investors in East Asia, in K.A. Froot, ed, Foreign Direct Investment (University of Chicago Press: Chicago) 